\title{
A REDUÇÃo dAS ÁREAS DE PRESERVAÇÃO PERMANENTE DE RECURSOS HÍDRICOS PELO NOVO CÓDIGO FLORESTAL E O PRINCÍPIO DA PROIBIÇÃO PROTEÇÃO DEFICIENTE
}

\author{
REDUCTION OF PERMANENT PRESERVATION AREAS OF WATER \\ RESOURCES BY THE NEW FOREST CODE AND THE PRINCIPLE OF \\ PROHIBITION OF INSUFFICIENT PROTECTION
}

\author{
Ana Maria D’Ávila Lopes* \\ Mônica Mota Tassigny** \\ Diego Monte Teixeira***
}

\begin{abstract}
Resumo: Este artigo objetiva discutir as principais mudanças promovidas pelo novo Código Florestal brasileiro (Lei $n^{0} 12.651 / 2012$ ) no regime das áreas de preservação permanente de recursos hídricos. Trata-se de pesquisa qualitativa e exploratória. A partir do estudo sobre as funções ambientais deste tipo de espaço, constatou-se que o revogado Código Florestal de 1965 previa parâmetros mínimos para a preservação dos processos ecológicos essenciais e a garantia de um ambiente hígido, sendo que o novo Código diminuiu ainda mais essa proteção, o que constitui uma afronta ao princípio da proibição de proteção deficiente (Untermaßverbot), já que se deixou de assegurar padrões mínimos adequados para a proteção do direito fundamental ao meio ambiente ecologicamente equilibrado, evidenciando a necessidade de uma reforma legislativa.
\end{abstract}

Palavras-chave: Áreas de Preservação Permanente; Recursos hídricos; Código Florestal; Proteção insuficiente; Untermaßverbot.

\footnotetext{
Abstract: The paper aims to discuss the main changes brought by the new Brazilian Forest Code (L. 12.651/2012) on the permanent preservation areas of water resources. It is a qualitative and exploratory research. From the research on the ecological functions of this type of area, notes that the repealed Forest Code of 1965 provided minimum standards for the preservation of essential ecological processes and the guarantee of a healthy environment, and the new code decreases further this protection, which constitutes an affront to the principle of

* Doutora e Mestre em Direito Constitucional pela Universidade Federal de Minas Gerais (UFMG). Professora Titular do Programa de Pós-Graduação em Direito na Universidade de Fortaleza (UNIFOR). Bolsista de Produtividade em Pesquisa do CNPq. E-mail: anadavilalopes@yahoo.com.br

** Doutora e Mestre em Educação pela Universidade Federal do Ceará e em Ciências Sociais Aplicadas pela Ecole des Hautes Etudes en Sciences Sociales (Paris). Professora Titular da Universidade de Fortaleza (UNIFOR) e colaboradora do Programa de Pós-Graduação em Direito Constitucional na Universidade de Fortaleza (UNIFOR). E-mail: monica.tass@gmail.com

**** Mestrando pelo Programa de Pós-Graduação Stricto Sensu em Direito Constitucional na Universidade de Fortaleza (UNIFOR). Analista do Ministério Público da União/Apoio Jurídico/Direito. E-mail: diegomontet@gmail.com
} 
A Redução das Áreas de Preservação Permanente de Recursos Hídricos pelo Novo Código Florestal e o Princípio da Proibição Proteção Deficiente

prohibition of insufficient protection (Untermaßverbot) because it fails to provide adequate minimum standards for protection of the fundamental right to an ecologically balanced environment, showing the need for legislative reform.

Keywords: Permanent Preservation Area; Water resources; Forest Code; Insufficient protection; Untermaßverbot.

\section{INTRODUÇÃO}

A partir das imposições ao Poder Público, pelo art. 225 da Constituição da República Federativa do Brasil de 1988, de deveres de proteção para a garantia do direito fundamental ao meio ambiente ecologicamente equilibrado, espera-se que o Estado adote medidas administrativas e legislativas que assegurem a efetividade desse direito, que está diretamente ligado à qualidade de vida humana.

A garantia dos direitos fundamentais contra a atuação do legislador que pretenda restringir os seus níveis de salvaguarda, para aquém dos padrões mínimos de proteção, revelase na doutrina como um princípio constitucional implícito de proibição da proteção deficiente (Untermaßverbot), nos moldes propostos por Canaris (2003). A partir desse princípio, o Estado se obriga a assegurar um nível mínimo adequado de tutela dos direitos fundamentais, responsabilizando-se pelas omissões legislativas que impliquem o não cumprimento dessa imposição constitucional.

Com o advento do Código Florestal de 2012, que flexibilizou a proteção de áreas de proteção permanente (APP) hídricas, surgiram questionamentos sobre a inconstitucionalidade da redução dos parâmetros de proteção em relação ao Código anterior. Contudo, na medida em que esses questionamentos não se fizeram acompanhar de uma análise sobre a repercussão prática das modificações dos padrões de qualidade ambiental, a argumentação em prol do direito fundamental ao meio ambiente ecologicamente equilibrado encontra resistência quando confrontada com o argumento genérico da necessidade do desenvolvimento sustentável, segundo o qual a proteção ao meio ambiente não deve ser compreendida como óbice ao desenvolvimento econômico, mas como forma de gestão racional de recursos naturais.

Por tal razão, invoca-se o princípio constitucional implícito da proporcionalidade, na sua acepção de proibição deficiente (Untermaßverbot), como importante barreira contra investidas legislativas que suprimam padrões mínimos de qualidade ambiental, colocando em risco o equilíbrio ecológico.

Nesse contexto, o objetivo do presente trabalho é discutir as consequências da R. Fac. Dir. UFG, v. 41, n.1, p. 46-65, jan. / jun. 2017

ISSN 0101-7187 
redução das Áreas de Preservação Permanente (APPs) de recursos hídricos pelo novo Código Florestal, aprovado em 2012.Tendo como norte os padrões de proteção das APPs pelo revogado Código Florestal de 1965, que, segundo diversos estudos científicos, estabeleciam já parâmetros mínimos para a preservação dos processos ecológicos essenciais a que se destinam esses espaços protegidos, pretende-se demonstrar que as mudanças promovidas pelo novo Código Florestal no regime das APPs de recursos hídricos afrontam o direito fundamental ao meio ambiente ecologicamente equilibrado, já que não o protegem de forma suficiente.

\section{AS MUdanÇAS NaS Áreas de PRESERVAÇÃo PERManente de RECURSOS HÍDRICOS PELA LEGISLAÇÃO FLORESTAL BRASILEIRA}

As primeiras normas de proteção dos recursos naturais em solo pátrio remontam aos séculos XVI e XVII, quando o Brasil era colônia portuguesa. Assim, relata Milaré (2005, p. 95-96) que, nas Ordenações Manuelinas de 1521, proibia-se a caça de certos animais e tipificava-se como crime o corte de árvores frutíferas. Já nas Ordenações Filipinas de 1603 proibia-se o depósito de materiais nos rios que pudessem provocar a morte de peixes e reiterava-se o crime pelo corte de árvores frutíferas. Durante o Império, outras normas foram também aprovadas, a exemplo das instruções para o plantio regular nas "Florestas da Tijuca e das Paineiras" a fim de recuperar os mananciais da cidade pelo reflorestamento (DRUMMOND, 1997, p. 221).

Apesar da importância dessas normas para a preservação dos recursos naturais, deve-se, entretanto, alertar que,

tinham seu fundamento no interesse econômico da preservação de uma fonte de riqueza, e não na essencialidade de um meio ambiente ecologicamente equilibrado como requisito essencial para a sadia qualidade de vida das presentes e futuras gerações, conforme hoje é disposto no caput do art. 225 da CF/88 (LOPES; ALENCASTRO, 2008, p. 9).

A motivação econômica da proteção dos recursos naturais foi uma constante durante grande parte da história jurídica brasileira, inclusive no período da República, conforme pode observar-se nos artigos $1^{\circ}$ e $2^{\circ}$ do primeiro Código Florestal brasileiro, Decreto $\mathrm{n}^{\circ} 23.793$, de 23 de janeiro de 1934 ,

Art. $1^{\circ}$ As florestas existentes no territorio nacional, consideradas em conjuncto, constituem bem de interesse commum a todos os habitantes, do paiz, exercendo-se 
A Redução das Áreas de Preservação Permanente de Recursos Hídricos pelo Novo Código Florestal e o Princípio da Proibição Proteção Deficiente

os direitos de propriedade com as limitações que as leis em geral, e especialmente este codigo, estabelecem.

Art. $2^{\circ}$ Applicam-se os dispositivos deste codigo assim às florestas como às demais formas de vegetação, reconhecidas de utilidade às terras que revestem (BRASIL, 1934, on-line).

A expressão "bem de interesse comum a todos habitantes do país" do art. $1^{\circ}$ refletia, à época, a preocupação do legislador com a crescente dilapidação do patrimônio florestal do país (AHRENS, 2010, p. 70), enquanto o trecho "de utilidade às terras que revestem" do art. $2^{\circ}$ evidencia a preocupação utilitarista da proteção.

Essa visão dos recursos naturais como apenas fontes de riqueza começou a ser superada somente na década de 1950. Lecionam Lopes, Alencastro e Araújo que,

\begin{abstract}
A preocupação com os recursos naturais, no Brasil e no Mundo, se fez refletir não apenas nos discursos dos movimentos ambientalistas, mas também infligiu significativas alterações no disciplinamento legal das condutas humanas capazes de repercutir sobre a base de recursos naturais. A lógica de apropriação e uso dos recursos naturais, pautada sempre na busca do lucro, passou a ser questionada a partir do direito de acesso a esses recursos das gerações atuais e futuras (LOPES; ALENCASTRO, 2008, p. 10).
\end{abstract}

Foi nesse marco contextual que se iniciaram os trabalhos de elaboração de um novo Código Florestal, aprovado pela Lei $\mathrm{n}^{\mathrm{o}} 4.771$ de 15 de setembro de $1965^{1}$, após 15 anos de ter sido apresentado ao congresso nacional o Projeto Daniel de Carvalho, no qual já se vislumbrava uma mudança de postura (AHRENS, 2010, p. 70).

Assim, é nesse Código de 1965 que foram criadas as Áreas de Preservação Permanente (APPs), cujos antecedentes podem ser encontrados no art. $4^{\circ}$ do Código Florestal de 1934.

Art. $4^{\circ}$ Serão consideradas florestas protectoras as que, por sua localização, servirem conjuncta ou separadamente para qualquer dos fins seguintes:

a) conservar o regimen das aguas;

b) evitar a erosão das terras pela acção dos agentes naturaes;

c) fixar dunas;

d) auxiliar a defesa das fronteiras, de modo julgado necessario pelas autoridades militares;

e) assegurar condições de salubridade publica;

f) proteger sitios que por sua belleza mereçam ser conservados;

g) asilar especimens raros de fauna indígena (BRASIL, 1934, on-line).

As denominas florestas protetoras do Código de 1934 seriam um esboço do que

\footnotetext{
${ }^{1}$ As modificações ao texto original da Lei $\mathrm{n}^{0} 4.771 / 65$ foram promovidas pela Lei $\mathrm{n}^{0} 5106$ de 02/09/66, Lei $\mathrm{n}^{\circ} 5868$ de 12/12/72, Lei n ${ }^{\circ} 5870$ de 26/03/73, Lei no 7511 de 07/07/86, Lei $n^{\circ} 7803$ de 18/07/89, Lei $n^{\circ} 7803$ de 18/07/89, Lei $n^{\circ}$ 9985 de 18/07/00 e Medida Provisória n ${ }^{\circ}$ 2166-67 de 24 de agosto de 2001.
}

R. Fac. Dir. UFG, v. 41, n.1, p. 46-65, jan. / jun. 2017 
mais tarde constituiriam as APPs no Código de 1965, cuja definição foi prevista no inc. II do $\S 2^{\circ}$ do art. $1^{\circ}$ : “área de preservação permanente: área protegida nos termos dos artigos $2^{\circ}$ e $3^{\circ}$ desta Lei, coberta ou não por vegetação nativa, com a função ambiental de preservar os recursos hídricos, a paisagem, a estabilidade geológica, a biodiversidade, o fluxo gênico de fauna e flora, proteger o solo e assegurar o bem-estar das populações humanas.” (BRASIL, 1965, on-line). No art. $2^{\circ}$, encontramos o que era considerado APP:

a) ao longo dos rios ou de qualquer curso d'água desde o seu nível mais alto em faixa marginal cuja largura mínima será:

1 - de 30 (trinta) metros para os cursos d'água de menos de 10 (dez) metros de largura;

2 - de 50 (cinquenta) metros para os cursos d'água que tenham de 10 (dez) a 50 (cinquenta) metros de largura;

3 - de 100 (cem) metros para os cursos d'água que tenham de 50 (cinquenta) a 200 (duzentos) metros de largura;

4 - de 200 (duzentos) metros para os cursos d'água que tenham de 200 (duzentos) a 600 (seiscentos) metros de largura;

5 - de 500 (quinhentos) metros para os cursos d'água que tenham largura superior a 600 (seiscentos) metros;

b) ao redor das lagoas, lagos ou reservatórios d'água naturais ou artificiais;

c) nas nascentes, ainda que intermitentes e nos chamados "olhos d'água", qualquer que seja a sua situação topográfica, num raio mínimo de 50 (cinquenta) metros de largura;

d) no topo de morros, montes, montanhas e serras;

e) nas encostas ou partes destas, com declividade superior a $45^{\circ}$, equivalente a $100 \%$ na linha de maior declive;

f) nas restingas, como fixadoras de dunas ou estabilizadoras de mangues;

g) nas bordas dos tabuleiros ou chapadas, a partir da linha de ruptura do relevo, em faixa nunca inferior a 100 (cem) metros em projeções horizontais;

h) em altitude superior a 1.800 (mil e oitocentos) metros, qualquer que seja a vegetação. (BRASIL, 1965, on-line)

O Parágrafo Único desse dispositivo também previa que, no caso de áreas urbanas e nas regiões metropolitanas e aglomerações urbanas, em todo o território abrangido, observar-se-ia o disposto nos respectivos planos diretores e leis de uso do solo, respeitados os princípios e limites mínimos estabelecidos no artigo $2^{\circ}$. Já o artigo $3^{\circ}$ estabelecia as APPs administrativas, que seriam consideradas de preservação quando assim declaradas por ato do Poder Público.

Por outro lado, no art. $4^{\circ}$ estabelecia-se que, nas APPs, só seria possível o desmatamento da vegetação com autorização do Poder Público, nos casos excepcionais de utilidade pública ou de interesse social, quando devidamente caracterizados e motivados em procedimento administrativo próprio, e comprovada a inexistência de alternativa técnica e locacional ao empreendimento proposto.

Em 2001, entretanto, editou-se a Medida Provisória n ${ }^{\circ} 2.166$ (BRASIL, 2001, on- 
A Redução das Áreas de Preservação Permanente de Recursos Hídricos pelo Novo Código Florestal e o Princípio da Proibição Proteção Deficiente

line), que alterou a redação dos incisos IV e $\mathrm{V}$ do artigo $1^{\circ}$, nos quais definiam-se os casos de utilidade pública e de interesse social, bem como se delegava ao CONAMA a regulamentação de outros casos excepcionais de intervenção humana nas APPs ${ }^{2}$.

A constitucionalidade dessa Medida Provisória foi questionada na Ação Direta de Inconstitucionalidade - ADI n. 3540 MC/DF (STF, 2005, on-line), de relatoria do Ministro Celso de Mello. Na ocasião, o Supremo Tribunal Federal não apenas declarou a constitucionalidade da Medida Provisória $n^{0}$ 2.166-67, mas assentou que, além dos requisitos estabelecidos no Código Florestal de 1965 para os casos excepcionais de desmatamento e ocupação de APPs, a integridade dos atributos que justificaram a instituição desse tipo de espaço não poderia ficar comprometida. Nesse momento histórico, já se encontrava em vigor a Constituição Republicana de 1988, que, nos termos do art. 225, §1º III(BRASIL, 1988, online), determinava como uma das incumbências do Poder Público a definição de espaços territoriais a serem especialmente protegidos, como forma de assegurar a efetividade do direito fundamental ao meio ambiente ecologicamente equilibrado.

Esses "espaços territoriais a serem especialmente protegidos" abrangem as APPs já fixadas pelo Código Florestal de 1965, com suas respectivas alterações legais, tendo em vista a idoneidade delas para garantir um meio ambiente ecologicamente equilibrado, considerando os serviços ambientais que mantêm ${ }^{3}$.

A Constituição de 1988 também atribuiu ao Ministério Público, no art. 129, III CF/88 (BRASIL, 1988, on-line), a função de promover o inquérito público e a ação civil pública para a proteção do meio ambiente e de outros interesses difusos e coletivos. E, pelo que se depreende do teor do Parecer do deputado federal Aldo Rebelo (PCdoB-SP), relator do Projeto de Lei $n^{\circ}$ 1876/99 e apensados, a cobrança do Ministério Público para a efetiva implementação do Código Florestal com o consequente incremento de fiscalização pelos órgãos ambientais foi um dos grandes catalisadores do debate sobre a revisão da legislação então vigente ${ }^{4}$. Nas palavras de Aldo Rebelo (on-line):

\footnotetext{
${ }^{2}$ Em 2006, o CONAMA editou a Resolução n ${ }^{\circ}$ 369, na qual regulamenta os casos excepcionais de utilidade pública, interesse social ou baixo impacto ambiental, que possibilitam a intervenção ou supressão de vegetação em APP (CONAMA, 2006, online).

${ }^{3}$ Serviços ambientais ou ecossistêmicos são "os benefícios diretos e indiretos obtidos pelo homem a partir dos ecossistemas. Dentre eles pode-se citar a provisão de alimentos, a regulação climática, a formação do solo, etc. [...] São, em última instância, fluxos de materiais, energia e informações derivados dos ecossistemas naturais e cultivados que, combinados com os demais tipo capital (humano, manufaturado e social) produzem o bem-estar humano" (ANDRADE; ROMEIRO, 2009).

${ }^{4} \mathrm{O}$ incremento da fiscalização ambiental propiciou a criação da definição de "área rural consolidada", que, por força do art. $3^{\circ}$, IV da Lei $\mathrm{n}^{\mathrm{o}}$ 12.651/2012 (BRASIL, 2012, on-line) passou a ser considerada a área de imóvel rural com ocupação antrópica preexistente à data da edição do Decreto $\mathrm{n}^{\circ}$ 6.514/08 em 22 de julho de 2008, que regulamentou a Lei de Crimes Ambientais e definiu as sanções administrativas e o processo administrativo federal para a apuração das sanções administrativas aos infratores ambientais (BRASIL, 2008, on-line).
} 
[...] Quando o Ministério Público começa a cobrar a efetiva implementação do Código Florestal e intensificam-se as ações de fiscalização, controle e punição, realizadas pelos órgãos ambientais, acelera-se o processo de debates e as tentativas de alteração das normas ambientais vigentes.

Diante desse panorama, alguns setores da economia brasileira, sobretudo os empresários do agronegócio, questionavam a Lei 4.771/65, tanto por uma suposta ausência de fundamentação científica, especialmente para a fixação de parâmetros das APPs, quanto por seu retalhamento por medidas provisórias, cujo resultado seria um emaranhado de normas contraditórias de difícil interpretação e, portanto, inaplicáveis (CARVALHO, 2014).

Tais questionamentos do setor do agronegócio ganharam corpo quando, em 2008, os pesquisadores da Embrapa divulgaram os resultados parciais de uma pesquisa realizada da própria Instituição que mostravam o alcance da legislação ambiental brasileira (MIRANDA, 2008). O trabalho concluía que se fossem unidas as diversas áreas protegidas brasileiras, como unidades de conservação, reservas indígenas, reservas legais e APPs, sobraria pouca área para a produção agrícola no país.

Foi nesse contexto que se elaborou o projeto de um novo Código Florestal (Projeto de Lei $\mathrm{n}^{\circ}$ 1876/99), cuja versão aprovada pela Câmara dos Deputados em 24 de maio de 2011 foi enviada ao Senado Federal e deu origem ao Projeto de Lei n ${ }^{\circ}$ 30/2011 (GARCIA, on-line). As discussões foram acirradas e geraram uma forte tensão entre os políticos da bancada ruralista e os simpatizantes das causas ambientalistas.

Após o êxito dos parlamentares que defendiam a alteração da legislação, com a consequente aprovação do novo Código Florestal por meio da Lei n 12.651/2012 (BRASIL, 2012, on-line), houve significativa alteração nas delimitações das APPs de recursos hídricos. Tanto ocorreu a diminuição de alguns tipos de APPs ripárias, como a própria exclusão de APPs nas chamadas nascentes intermitentes, quanto foi ainda instituído o conceito de área rural consolidada para a desobrigação de recomposição das APPs indevidamente ocupadas antes de 22 de julho de 2008.

Apesar do art. $3^{\circ}$, II, do novo Código Florestal, praticamente repetir o conceito de APPS previsto no anterior Código, o dispositivo do art. $4^{\circ}$ trouxe alterações significativas na legislação florestal.

Assim, a alteração do parâmetro de medição das APPs a partir da borda da calha do leito regular do curso d'água, e não mais a partir do seu nível mais alto, reduz substancialmente essas áreas protegidas. Tal redefinição acarretará a possibilidade de ocupação do leito maior de cursos d'água, sujeito a inundações no período de cheias. 
A Redução das Áreas de Preservação Permanente de Recursos Hídricos pelo Novo Código Florestal e o Princípio da Proibição Proteção Deficiente

Com relação às APPs dos reservatórios d'água artificiais, cuja faixa no seu entorno deverá ser definida na licença ambiental do empreendimento, não se estipulou um padrão mínimo de proteção. Além disso, dispensou-se a necessidade de reservar uma faixa de proteção no entorno das acumulações naturais ou artificiais de água com superfície inferior a 1 (um) hectare, desde que não impliquem nova supressão de vegetação nativa sem autorização do órgão ambiental competente.

Outra alteração bastante relevante é a que extinguiu as APPs nos afloramentos naturais d'água subterrânea intermitentes, mantendo-se a necessidade da APP em um raio mínimo de 50 (cinquenta) metros apenas no entorno das nascentes e olhos d'água perenes. Da análise dos conceitos de nascente e olho d'água, conferidos pelo art. $3^{\circ}$, XVII e XVIII da Lei $\mathrm{n}^{\mathrm{o}}$ 12.651, denota-se que foi retirado o caráter de intermitência do conceito de nascente, mantendo-se somente para olho d'água.

Além do regime jurídico geral das APPs de recursos hídricos, já bastante flexibilizado em comparação ao revogado Código Florestal de 1965, sobretudo quando se observa que foram ampliadas em demasia as hipóteses de utilidade pública, interesse social e atividade eventual ou de baixo impacto que permitem a intervenção em APPs (conforme rol exemplificativo do artigo $3^{\circ}$, incisos VIII, IX e X, da Lei $\left.\mathrm{n}^{\circ} 12.651 / 2012\right)$, também foi estabelecido um regime de transição nos artigos 59 a 65 , com a relativização da proteção desses espaços protegidos.

Pelo que se depreende das redações dos artigos 61-A a 65 do novo Código Florestal, foram instituídas diversas hipóteses de legitimação da continuidade de obras e atividades em APPs das chamadas áreas rurais consolidadas até 22 de julho de 2008.

No que pertine às APPs ao longo dos cursos d'água naturais e de lagos e lagoas naturais em áreas rurais consolidadas, observa-se que, para os imóveis rurais de até quatro módulos fiscais, as faixas a serem obrigatoriamente recompostas variam de 5 (cinco) a 15 (quinze) metros de largura, contados da borda da calha do leito regular, independentemente da largura do rio, de acordo com o seguinte escalonamento: até 1 (um) módulo fiscal, recomposição de 5 (cinco) metros; entre 1 (um) e 2 (dois) módulos fiscais, recomposição de 8 (oito) metros; entre 2 (dois) e 4 (quatro) módulos fiscais, recomposição de 15 (quinze) metros.

Nos casos de áreas rurais consolidadas em APP no entorno de nascentes e olhos d'água perenes, será admitida a manutenção de atividades agrossilvipastoris, de ecoturismo ou de turismo rural, sendo obrigatória a recomposição do raio mínimo de 15 (quinze) metros (art. 61-A, $\left.\S 5^{\circ}\right)$.

R. Fac. Dir. UFG, v. 41, n.1, p. 46-65, jan. / jun. 2017 
Com relação às veredas ${ }^{5}$, nos imóveis de até 4 (quatro) módulos fiscais bastará a recomposição das faixas marginais de 30 (trinta) metros, ao invés de 50 (cinquenta) metros previstos na legislação revogada.

O artigo 61-B do Código, com a redação conferida pela Lei $n^{0} 12.727 / 2012$, assenta que, no caso de imóveis rurais que, em 22 de julho de 2008, detinham até 4 (quatro) módulos fiscais, a recomposição obrigatória de que trata o artigo 61-A, somadas todas as APPs, hídricas ou não, não poderá ultrapassar: I - 10\% (dez por cento) da área total do imóvel, para imóveis rurais até 2 (dois) módulos fiscais; e II - 20\% (vinte por cento) da área total do imóvel, para imóveis rurais entre 2 (dois) e 4 (quatro) módulos fiscais. É dizer: a recomposição da vegetação da APP se dará respeitando-se os interesses individuais dos proprietários dos imóveis, ainda que o interesse púbico ambiental reclame providência diversa.

Tendo em vista a situação inusitada criada pelo novo Código Florestal, de tratar melhor os proprietários de imóveis que violaram o Código Florestal de 1965 em detrimento dos que obedeceram à legislação, como a possibilidade de manutenção de uma faixa menor de APP a partir da consolidação de atividades degradadoras do meio ambiente, Edson Ferreira Carvalho (2014, p. 262) apreende o triste fenômeno criativamente com a denominação do "princípio da degradação premiada".

\section{AS FUnÇÕES AMBIENTAIS DAS ÁREAS DE PRESERVAÇÃo PERMANENTE DE RECURSOS hídricos E A DEFINIÇÃo DE FAIXAS MÍNIMAS DE PROTEÇÃO}

As funções ambientais das APPs encontram-se previstas no art. $3^{\circ}$, II, do Código Florestal vigente: preservar os recursos hídricos, a paisagem, a estabilidade geológica e a biodiversidade, facilitar o fluxo gênico de fauna e flora, proteger o solo e assegurar o bemestar das populações humanas (BRASIL, 2012, on-line).

Segundo aponta a Sociedade Brasileira para o Progresso da Ciência (SBPC) e a Academia Brasileira de Ciências (ABC), as APPs protegem áreas mais frágeis ou estratégicas,

\footnotetext{
${ }^{5}$ Nos termos do art. $3^{\circ}$, XII do Código Florestal (BRASIL, 2012, on-line), considera-se vereda "a fitofisionomia de savana, encontrada em solos hidromórficos, usualmente com a palmeira arbórea Mauritia flexuosa - buriti emergente, sem formar dossel, em meio a agrupamentos de espécies arbustivo-herbáceas". Trata-se de um conceito novo que altera o anteriormente definido na Resolução n $\mathrm{n}^{\circ}$ 303/2002 (CONAMA, 2002, on-line), o qual era mais amplo, e tratava, no inciso III do art. $2^{\circ}$, esse tipo de sítio como o "espaço brejoso ou encharcado, que contém nascentes ou cabeceiras de cursos d’água, onde há ocorrência de solos hidromórficos, caracterizado predominantemente por renques de buritis do brejo (Mauritia flexuosa) e outras formas de vegetação típica."
}

R. Fac. Dir. UFG, v. 41, n.1, p. 46-65, jan. / jun. 2017

ISSN 0101-7187 
A Redução das Áreas de Preservação Permanente de Recursos Hídricos pelo Novo Código Florestal e o Princípio da Proibição Proteção Deficiente

como aquelas com maior risco de erosão de solo ou que servem para recarga de aquífero, seja qual for a vegetação que as recobre, além de terem papel importante de conservação da biodiversidade (SILVA, 2008, p. 80).

Para a proteção dos recursos hídricos, as APPs são criadas, sobretudo, para a preservação das matas ciliares, que podem ser compreendidas como sistemas de vegetações estabelecidos naturalmente em faixas às margens dos rios e riachos, no entorno de lagos, represas e nascentes, exercendo função de instrumento redutor do assoreamento e da degradação do meio ambiente e como meio natural de processamento e transformação da diversidade ambiental (CASTRO, 2013, p. 230). A mata ciliar protege os rios, lagos e nascentes, cobrindo e protegendo o solo, deixando-o fofo e permitindo que funcione como uma esponja que absorve a água das chuvas. Com isso, além de regular o ciclo da água, evita as enxurradas e propicia a formação de corredores ecológicos para plantas e animais (CAMPANILI; SCHAFFER, 2010, p. 22).

Quanto à função hidrológica, as matas ciliares são responsáveis pela manutenção da integridade da microbacia hidrográfica, preservando a qualidade e a quantidade de água nela contida, bem como do ecossistema aquático (LIMA; ZAKIA, 2000).

As relações da presença da vegetação no fluxo dos rios foram quantificadas em estudos desenvolvidos por Likens et al. (1992), em 1990, na reserva ecológica Hubbard Brook, dos Estados Unidos da América, para demonstrar que o volume de água dos rios mantém-se aproximadamente constante durante o ciclo estacional, devido ao fator regulador da vegetação na quantidade de água escoada. Enquanto que estudos físico-químico e ecológico dos rios da bacia hidrográfica do Ribeirão e represa do Lobo, desenvolvidos por Tundisi e Tundisi, no ano de 1988, demonstraram que a qualidade da água está diretamente relacionada com a presença da vegetação ripária e sua densidade ao longo do rio (TUNDISI; TUNDISI, 2010, p. 68).

Dessa forma, eventual remoção de vegetação em áreas alagadas para o aumento de área agrícola compromete a qualidade d'água superficial e subterrânea, bem como a sua reposição nos aquíferos, provocando a perda de solo e a degradação dos mananciais, o que no futuro exigirá sistemas de tratamento mais sofisticados e de custo mais elevado, em contraposição ao papel regulador dos ciclos naturais realizado pelas florestas e áreas alagadas rio (TUNDISI; TUNDISI, 2010, p. 74).

No que se refere à relação da qualidade da água com a saúde humana, estima-se que $80 \%$ (oitenta por cento) de todas as moléstias e mais de um terço dos óbitos dos países em 
desenvolvimento sejam causados pelo consumo de água contaminada e, em média, até um décimo do tempo produtivo de cada pessoa se perde devido a doenças relacionadas à água (MORAES; JORDÃO, 2002, p. 372).

Em estudo realizado por docentes da Escola Superior de Agricultura "Luiz de Queiroz”, da Universidade de São Paulo (ATTANASIO, 2006, p. 137), os pesquisadores demonstram que a largura da mata ciliar determinada pelo Código Florestal de 1965 como de preservação permanente poderia eventualmente ser apropriada para proteger os cursos d' água, mas sequer seria suficiente para resguardar áreas hidrologicamente sensíveis da microbacia.

A dificuldade em se estabelecer a largura ótima para a faixa de mata ciliar, tal qual demonstram diversos estudos científicos, dá-se pela necessidade de se levar em consideração caso a caso os atributos morfológicos da bacia hidrográfica (MOMOLI, 2011, p. 24).

Muito embora as matas ciliares tenham diversas outras funções ambientais, como a de preservar a paisagem, a de permitir a estabilidade geológica, e a de proteger o solo, são as funções ambientais de preservar a biodiversidade e assegurar o fluxo gênico de fauna e flora, servindo de "corredores ecológicos" entre fragmentos florestais e unidades de conservação", que têm despertado uma maior atenção dos cientistas quanto à definição de parâmetros mínimos desses espaços protegidos no entorno de recursos hídricos.

Sob esse especial aspecto, cumpre ao aplicador do Direito observar os diversos estudos científicos que apontam para a necessidade de faixas de vegetação com conectividade de limites mínimos de pelos menos 100 (cem) metros (cinquenta metros de cada lado do rio), independentemente do bioma, do grupo taxonômico, do solo ou do tipo de topografia, para a conservação da biodiversidade (METZGER, 2010).

O trabalho do ecologista Jean Paul Metzger (2010), além de apontar que a conservação da biodiversidade é provavelmente um dos fatores mais limitantes para a definição de larguras mínimas de APPs, concluiu que, para a maioria das espécies de plantas e vertebrados, a faixa de no mínimo 30 (trinta) metros ao lado de cursos d'água, antes prevista pelo Código Florestal de 1965, geralmente, sequer seria suficiente para assegurar a

\footnotetext{
${ }^{6}$ Tal qual previsto na Resolução CONAMA nº 9/1996 (CONAMA, 1996, on-line), os corredores ecológicos se prestam a manter a conectividade entre remanescentes de vegetação entre as matas ciliares e aquelas existentes nas unidades de conservação da natureza.

${ }^{7}$ Nos termos do art. $2^{\circ}$, XIX, da Lei $n^{\circ}$ 9.985/2000 (BRASIL, 2000, on-line), os corredores ecológicos são porções de ecossistemas naturais ou seminaturais, ligando unidades de conservação, que possibilitam entre elas o fluxo de genes e o movimento da biota, facilitando a dispersão de espécies e a recolonização de áreas degradadas, bem como a manutenção de populações que demandam para sua sobrevivência áreas com extensão maior do que aquela das unidades individuais.
}

R. Fac. Dir. UFG, v. 41, n.1, p. 46-65, jan. / jun. 2017

ISSN 0101-7187 
A Redução das Áreas de Preservação Permanente de Recursos Hídricos pelo Novo Código Florestal e o Princípio da Proibição Proteção Deficiente

manutenção dessa biodiversidade em longo prazo, e tampouco para promover a conectividade da paisagem.

Com efeito, algumas pesquisas sobre os impactos potenciais das mudanças propostas no Código Florestal sobre a ecologia e a conservação da diversidade dos mamíferos (GALETTI, on-line), da ictiofauna (CASATTI, on-line), das borboletas (FREITAS, on-line) e dos anfíbios (TOLEDO, on-line) no Brasil reforçam as graves consequências da redução de áreas com vegetação nativa, com a consequente extinção de várias espécies e o aumento no risco de transmissão de doenças.

No mesmo sentido, para os pesquisadores da SBPC e ABC (SILVA, 2011, p. 48) o anterior Código Florestal já continha valores mínimos de proteção insuficientes para a proteção das zonas ripárias de forma cientificamente substanciada, o que com o novo Código agravou-se.

\section{O PRINCÍPIO DA PROIBIÇÃO DA PROTEÇÃO DEFICIENTE (UNTERMAßVERBOT) E A REDUÇÃO LEGAL DAS ÁREAS DE PRESERVAÇÃO PERMANENTE}

Já estão sendo publicados os primeiros estudos que demonstram, do ponto de vista quantitativo, a diminuição das APPs de recursos hídricos pelo Código Florestal de 2012. Em dois estudos de casos publicados no final de 2013 (GARCIA, 2013): o primeiro envolvendo duas unidades de manejo de recursos hídricos, no Estado de São Paulo, uma no Cerrado e outra na Mata Atlântica; e o segundo abrangendo 57 (cinquenta e sete) pequenas propriedades privadas em Mato Grosso, Minas Gerais, Bahia e Distrito Federal, os cientistas efetuaram uma comparação entre as regras do Código Florestal anterior (Lei $\left.n^{\circ} 4.771 / 65\right)$ e as do vigente (Lei ${ }^{0}$ 12.651/2012), para demonstrar que houve uma redução de cerca de 50\% (cinquenta por cento) da extensão a ser restaurada em função da mudança da largura das APPs.

Também, a título ilustrativo, estudiosos do Departamento de Ciências Ambientais da Universidade Federal de São Carlos (FARIA, 2014), ao analisarem os reflexos das alterações legais nas APPs de duas propriedades rurais em Itu e Sarapuí, São Paulo, constataram que foram reduzidas as APPs de alguns elementos da paisagem nas duas propriedades avaliadas, e que houve fragmentação da APP no entorno de cursos d'água em uma delas.

Assim, não restam dúvidas quanto aos efeitos quantitativos da redução de APPs 
de recursos hídricos a partir das novas regras do Código Florestal. Os efeitos qualitativos sobre a quantidade e a qualidade d'água, sobre a biodiversidade e a saúde humana ainda serão evidenciados com o avançar do tempo e com a sinergia dos impactos cumulativos em diversas áreas fragmentadas.

Na seara normativa, desde a publicação da Política Nacional de Meio Ambiente, Lei $n^{\circ}$ 6.938/81 (BRASIL, 1981, on-line), já existe no país uma diretriz legal para que as ações de desenvolvimento econômico-social sejam compatibilizadas com a preservação da qualidade ambiental e do equilíbrio ecológico, para a garantia de utilização racional e permanente dos recursos naturais (art. $4^{\circ}$, I e VI). Tal diretriz passou a ter envergadura constitucional em 1988, no âmbito dos princípios que regem a atividade econômica do país, nos termos do art. 170, VI da CF/88(BRASIL 1988, on-line).

As obrigações impostas ao Poder Público pelo $\S 1^{\circ}$ do artigo 225 da CF/88 (BRASIL 1988, on-line) revelam que, para além dos deveres de abstenção do Estado em não promover atividades degradadoras do meio ambiente, deve adotar medidas concretas para a garantia do direito fundamental ao meio ambiente ecologicamente equilibrado, mediante a restauração dos processos ecológicos essenciais, definição de espaços territoriais a serem especialmente protegidos, adoção de medidas eficientes para evitar a poluição, dentre outras.

O Poder Público tem, portanto, a obrigação constitucional de proteger adequadamente o meio ambiente. Quando essa proteção é insuficiente, viola-se o princípio da proibição da proteção deficiente (Untermaßverbot). Esse princípio

opera como ferramenta dogmática extraída do mandado de proporcionalidade e que nessa condição predispõe-se a funcionar como um parâmetro no controle (de constitucionalidade) de determinados atos estatais que eliminem ou deixem de concretizar a proteção necessária ao adequado e eficaz desenvolvimento do direito fundamental (FELDENS, 207, p. 222).

Segundo Vieira de Andrade (2009, p. 140), pelo princípio da proibição da proteção deficiente (Untermaßverbot), o Estado se obriga a assegurar um nível mínimo adequado de tutela dos direitos fundamentais, responsabilizando-se pelas omissões legislativas que impliquem o não cumprimento dessa imposição constitucional.

Além das omissões, o princípio auxilia também na determinação das eventuais distorções que a atividade legislativa pode provocar na regulação dos direitos fundamentais (GAVARA DE CARA, 2007, p. 228).

Ora, com o advento do novo Código Florestal, que flexibilizou a utilização de 
A Redução das Áreas de Preservação Permanente de Recursos Hídricos pelo Novo Código Florestal e o Princípio da Proibição Proteção Deficiente

áreas que poderiam ser de sobremodo úteis aos ecossistemas caso ficassem imunes ao manejo pelos seres humanos, resta evidente que o legislador infraconstitucional incorreu em prática inconstitucional na implementação do direito fundamental ao meio ambiente ecologicamente equilibrado, na medida em que diminuiu os standards mínimos antes estabelecidos pelo Código Florestal de 1965 para a proteção das APPs de recursos hídricos.

A partir da análise específica das alterações legais das APPs de recursos hídricos, com o devido embasamento em estudos científicos, observa-se quão deficientes se tornaram os novos níveis de proteção da norma, sem que se obtivessem grandes níveis de satisfação de outro direito fundamental.

Nem mesmo a invocação ao estudo da EMBRAPA (citado linhas acima deste trabalho) de que existiria pouca área para o desenvolvimento agrícola e, consequentemente, estar-se-ia desobedecendo o objetivo fundamental do Brasil referente ao desenvolvimento nacional, previsto no inciso II do art. $3^{\circ}$ da CF/88 (BRASIL 1988, on-line), justifica a proteção deficiente das APPs. Tanto a Lei revogadora atinge o núcleo essencial do direito fundamental ao meio ambiente ecologicamente equilibrado, como o próprio argumento que invoca o princípio do desenvolvimento nacional parece equivocado, pois, mesmo que se aplicassem na íntegra as regras das áreas protegidas pelo anterior Código, ainda sobrariam 103 (cento e três) milhões de hectares sem proteção, terras privadas com vegetação natural que poderiam ser legalmente desmatadas (SPAROVEK, on-line).

A desproporção do novo Código Florestal em relação às APPs de recursos hídricos é tamanha que, nas regiões em que a agricultura está consolidada, onde há os maiores déficits de APP e a maior demanda por água, houve a diminuição das larguras dos espaços protegidos. Da mesma forma, em tempos de escassez de água ${ }^{8}$ e de deterioração em massa da biodiversidade ${ }^{9}$, admitir a redução das matas ciliares ao longo dos cursos hídricos pelo novo Código Florestal, em descompasso com tantos estudos que demonstram que o Código revogado continha padrões mínimos de proteção, é o atestado da insuficiência de proteção do

\footnotetext{
8 Em 20 de março de 2015, o Conectas Direitos Humanos e a Aliança pela Água, coletivos de organizações não governamentais do qual a WWF-Brasil, faz parte, denunciaram a crise hídrica de São Paulo durante a $28^{a}$ Sessão do Conselho de Direitos Humanos da Organização das Nações Unidas (ONU). Em um dos trechos da declaração das referidas ONGs menciona-se a iminente situação de colapso no abastecimento de água na região metropolitana de São Paulo, a mais rica do país, ameaçando o direito humano de milhões de pessoas ao acesso à água, e aponta como causas desse problema o uso indevido da água e as políticas irresponsáveis de conservação, que, por décadas, favoreceram o desmatamento, a ocupação ilegal nas margens de rios e a poluição da água (WWF - BRASIL, on-line).

${ }^{9}$ Segundo Edward Osborne Wilson (1997), três são os motivos que justificam a proteção da biodiversidade como assunto urgente sem precedentes: a) o grande aumento da população, que está desgastando o meio ambiente de forma muito acelerada, especialmente nos países tropicais; b) o segundo são as novas descobertas da ciência para o uso da biodiversidade que, embora objetivem diminuir sofrimento humano, provocam a destruição ambiental; e, c) a perda irreversível da biodiversidade pela extinção de habitats inteiros, especialmente acentuada nos trópicos.
}

R. Fac. Dir. UFG, v. 41, n.1, p. 46-65, jan. / jun. 2017 
direito fundamental (Untermaßverbot) ao meio ambiente equilibrado e a violação ao seu conteúdo essencial pelo Estado-legislativo.

Viola-se o conteúdo essencial de um direito fundamental quando não pode mais ser exercido, protegido ou quando seu exercício tem sido dificultado além do razoável (LOPES, 2004, p. 7). Aí é que ganha relevo o princípio do mínimo existencial para o alcance da proteção contra medidas estatais que resultem na anulação, revogação ou aniquilação desse núcleo essencial. Tal núcleo essencial abrange bem mais do que a garantia da mera sobrevivência física e não pode ser restringido à noção de um mínimo vital (SARLET; FENSTERSEIFER, 2011, p. 40) Mais do que isso, em termos ambientais, é necessária uma sobrevivência de qualidade e a manutenção das bases para que a vida humana continue a se perpetuar.

\section{CONCLUSÃO}

A proteção dos recursos naturais é uma constante na história no Brasil. Contudo, ao longo dos séculos, é possível constatar como essa proteção foi mudando. Assim, não apenas os fundamentos da proteção foram se alterando, passando de interesses meramente econômicos ao respeito à dignidade humana, mas também os mecanismos de preservação desses recursos foram se ampliando. Dentre esses, cita-se a Área de Preservação Permanente (APP).

As APPs têm seus antecedentes no Código Florestal de 1934, no qual se criaram as chamadas florestas protetoras. É no segundo Código Florestal, aprovado em 1965, que a tipologia das APPs foi instituída, assim como delimitaram-se os espaços mínimos em que não seriam admitidos o manejo pelos seres humanos. Em matéria de proteção de recursos hídricos, grandes avanços foram conquistados com a Lei $\mathrm{n}^{\circ} 7.511 / 86$, que aumentou as faixas de APPs situadas ao longo de cursos d'água, e a Lei $\mathrm{n}^{\mathrm{o}}$ 7.803/89, que instituiu novas tipologias de APPs, como no entorno das nascentes, ainda que intermitentes.

Esses avanços deflagraram a necessidade de uma maior fiscalização do Ministério Público para o efetivo cumprimento da legislação florestal e ensejaram o início das discussões sobre uma falta de cientificidade dos critérios legais para a proteção de certos espaços protegidos. Com tal argumento, alguns setores da economia agropecuária passaram a exigir a flexibilização da legislação ambiental para não barrar o desenvolvimento econômico do país.

Foi nesse contexto que, desconsiderando aspectos de ordem constitucional e R. Fac. Dir. UFG, v. 41, n.1, p. 46-65, jan. / jun. 2017 
A Redução das Áreas de Preservação Permanente de Recursos Hídricos pelo Novo Código Florestal e o Princípio da Proibição Proteção Deficiente

científicos, aprovou-se um novo Código Florestal em 2012, que, além de desconhecer várias das conquistas de proteção ambiental, como a necessidade de restauração de áreas degradadas, reduziu os níveis de proteção das APPs de recursos hídricos. A medida levada a cabo pelo Estado-legislador, além de ser um retrocesso socioambiental capaz de comprometer a qualidade do ambiente para as futuras gerações, prejudica a própria integridade dos atributos que justificaram a instituição desse tipo de espaço especialmente protegido.

A diminuição dos padrões de proteção das APPs de recursos hídricos empreendida pelo novo Código Florestal constitui uma violação ao princípio da proibição da proteção deficiente (Untermaßverbot), pois coloca em risco o núcleo essencial do meio ambiente ecologicamente equilibrado ao deixá-lo praticamente desprotegido, o que demonstra a urgente necessidade de uma mudança legislativa.

\section{REFERÊNCIAS}

AHRENS, S. O Código Florestal brasileiro no século XXI: histórico, fundamentos e perspectivas. In: FIGUEIREDO, G. J. P. et. al. (Org.). Código Florestal: 45 anos: estudos e reflexões. Curitiba: Letra da Lei, 2010. p. 63-82.

ANDRADE, José Carlos Vieira de. Os direitos fundamentais na Constituição Portuguesa de 1976. $4^{\mathrm{a}}$ ed., Almedina: Coimbra, 2009.

ANDRADE, Daniel Caixeta; ROMEIRO, Ademar Ribeiro. Serviços ecossistêmicos e sua importância para o sistema econômico e o bem estar humano. Texto para Discussão. São Paulo: Instituto de Economia-Universidade Estadual de Campinas (UNICAMP), 2009.

ATTANASIO, Cláudia Mira. et al. Método para a identificação da zona ripária: microbacia hidrográfica do Ribeirão São João (Mineiros do Tietê, SP). Scientia Forestalis, n. 71, p. 131140, ago. 2006.

BRASIL. Lei $n^{o} 12.651$, de 25 de maio de 2012. Dispõe sobre a proteção da vegetação nativa. Brasília, DF, 2012. Disponível em: http://www.planalto.gov.br/ccivil_03/_ato20112014/2012/lei/l12651.htm Acesso em: 13 nov. 2015.

BRASIL. Decreto Federal $n^{o}$ 6.514, de 22 de julho de 2008. Dispõe sobre as infrações e sanções administrativas ao meio ambiente, estabelece o processo administrativo federal para apuração destas infrações, e dá outras providências. Disponível em: http://www.planalto.gov.br/ccivil_03/_ato2007-2010/2008/ decreto/D6514.htm Acesso em: 13 nov. 2015.

BRASIL. Medida Provisória $n^{\circ}$ 2.166-67, de 24 de agosto de 2001. Altera os arts. $1^{\circ}, 4^{\circ}, 14$, 16 e 44, e acresce dispositivos à Lei $\mathrm{n}^{\circ} 4.771$, de 15 de setembro de 1965, que institui o Código Florestal, bem como altera o art. 10 da Lei $\mathrm{n}^{\circ}$ 9.393, de 19 de dezembro de 1996, que 
dispõe sobre o Imposto sobre a Propriedade Territorial Rural - ITR, e dá outras providências. Disponível em: http://www2.camara.leg.br/legin/fed/medpro/2001/medidaprovisoria-216667-24-agosto-2001-393708-publicacaooriginal-1-pe.html Acesso em: 13 jan. 2016.

BRASIL. Lei $n^{\circ}$ 9.985, de 18 de julho de 2000. Regulamenta o art. 225, $\S 1^{\circ}$, incisos I, II, III e VII da Constituição Federal, institui o Sistema Nacional de Unidades de Conservação da Natureza e dá outras providências. Disponível em: http://www.planalto.gov.br/ccivil_03/LEIS/L9985.htm Acesso em: 13. jan. 2016.

BRASIL. Constituição da República Federativa do Brasil, de 5 de outubro de 1988. Disponível em: http://www.planalto.gov.br/ccivil_03/Constituicao/Constituicao.htm Acesso em: 13 jan. 2016.

BRASIL. Lei $n^{0}$ 6.938. de 31 de agosto de 1981. Dispõe sobre a Política Nacional do Meio Ambiente, seus fins e mecanismos de formulação e aplicação, e dá outras providências. Disponível em: http://www.planalto.gov.br/ccivil_03/LEIS/L6938.htm Acesso em: 13 jan. 2016.

BRASIL. Lei $n^{\circ}$ 4.771, de 15 de setembro de 1965. Instituiu o código florestal brasileiro. Brasília, DF, 1965. Disponível em: http://www.planalto.gov.br/ccivil_03/Leis/L4771.htm Acesso em: 13 nov. 2015.

BRASIL. Decreto Federal $n^{\circ}$ 23.793, de 23 de janeiro de 1934. Decreta o código florestal. Brasília, DF, 1934. Disponível em: http://www.planalto.gov.br/ccivil_03/decreto/19301949/d23793.htm Acesso em: 13 nov. 2015.

CAMPANILI, Maura; SCHAFFER, Wigold Bertoldo. Mata Atlântica: patrimônio nacional dos brasileiros. Brasília: MMA, 2010.

CANARIS, Claus-Wilhelm. Direitos fundamentais e direito privado. Coimbra: Almedina, 2003.

CARVALHO, Edson Ferreira. Código Florestal, Relative Verfassungswidrigkeit "and” die Unterschieldlichkeit der Regelung: o tiro pode sair pela culatra. Revista de Direito Ambiental. v. 19, n. 75, jul/set, p. 261-287, 2014.

CASATTI, L. Alterações no Código Florestal Brasileiro: impactos potenciais sobre a ictiofauna. Biota Neotrop. 10(4). Disponível em: http://www.biotaneotropica.org.br/v10n4/pt/abstract?article+bn00310042010 Acesso em: 04 dez. 2015.

CASTRO, Martha Nascimento. et al. A importância da mata ciliar no contexto da conservação do solo. Revista Eletrônica de educação da Faculdade Araguaia. v. 4, n. 4, p. 230-241, 2013.

CONAMA - Conselho Nacional de Meio Ambiente. Resolução $n^{\circ}$ 369, de 28 de março de 2006. Dispõe sobre os casos excepcionais, de utilidade pública, interesse social ou baixo impacto ambiental, que possibilitam a intervenção ou supressão de vegetação em Área de Preservação Permanente - APP. Brasília, DF, 2006. Disponível em: http://www.mma.gov.br/port/conama/legiabre.cfm?codlegi=489. Acesso em: 13 nov. 2015.
R. Fac. Dir. UFG, v. 41, n.1, p. 46-65, jan. / jun. 2017
ISSN 0101-7187 
A Redução das Áreas de Preservação Permanente de Recursos Hídricos pelo Novo Código Florestal e o Princípio da Proibição Proteção Deficiente

CONAMA. Conselho Nacional de Meio Ambiente. Resolução no 303/2002, de 20 de março de 2002. Disponível em: http://www.mma.gov.br/port/conama/res/res02/res30302.html Acesso em: 14 jan. 2016.

CONAMA. Conselho Nacional de Meio Ambiente. Resolução $n^{\circ}$ 9, de 24 de outubro de 1996. Disponível em: http://www.mma.gov.br/port/conama/res/res96/res0996.html Acesso em: 14 jan. 2016.

DRUMMOND, José Augusto. Devastação e preservação ambiental: os Parques Nacionais do Estado do Rio de Janeiro. Niterói: EdUFF, 1997.

FARIA, Luiz Carlos de., et al. Reflexos das alterações no Código Florestal Brasileiro em Áreas de Preservação Permanentes de duas propriedades rurais em Itu e Sarapuí, SP. Rev. Ambient. Água, Taubaté, v. 9, n. 3, p. 559-568, set. 2014.

FELDENS, Luciano. Deveres de proteção penal na perspectiva dos tribunais internacionais de direitos humanos. Direitos Fundamentais \& Justiça. n. 1, p. 214-230, out/dez, 2007

FREITAS, A.V. L. Impactos potenciais das mudanças propostas no Código Florestal Brasileiro sobre as borboletas. Biota Neotrop. 10(4). Disponível em http://www.biotaneotropica.org.br/v10n4/pt/abstract?article+bn00810042010. Acesso em: 04 dez. 2015.

GALETTI, M. et. al. Mudanças no Código Florestal e seu impacto na ecologia e diversidade dos mamíferos no Brasil. Disponível em: http://www.biotaneotropica.org.br/v10n4/pt/abstract?article+bn00710042010. Acesso em: 04 dez. 2015.

GARCIA, Yara Manfrin. O Código Florestal brasileiro e suas alterações no Congresso Nacional. Geoatos. n. 12, v.1, janeiro a junho de 2012, p. 54-74. Disponível em: http://revista.fct.unesp.br/index.php/geografiaematos/article/viewFile/1754/iarama. Acesso em: 14 jan. 2016.

GARCIA, L.C. et. al. Changes in the Brazilian environmental law will affect ecosystem restoration and landscape integrity. Natureza \& Conservação. v. 11, n. 2, p. 181-185, 2013.

GAVARA DE CARA, Juan Carlos. La vinculación positiva de los poderes públicos a los derechos fundamentales. UNED. Teoría y Realidad Constitucional. n. 20, p. 177-320, 2007.

LIKENS, G. E. The ecosystem approach: its use and abuse. Excellence in Ecology. v. 3. Ecology Institute: Oldendorf/Luhe, 1992.

LIMA, W. P.; ZAKIA, M. J. B. Hidrologia de matas ciliares. In: RODRIGUES, R. R.; LEITÃ̃ FILHO, H. F (orfg). Matas ciliares: conservação e recuperação. São Paulo: EDUSP/FAPESP. 3 ed., 2000, p. 33-44.

LOPES, Ana Maria D’Ávila; ALENCASTRO, Maria Alice Cruz; ARAÚJO, Rogério César Pereira de. O licenciamento ambiental em áreas de assentamento de reforma agrária no Estado R. Fac. Dir. UFG, v. 41, n.1, p. 46-65, jan. / jun. 2017 
do Ceará. Revista de Direito Ambiental, v. 13. n 50, p. 9-27, abr/jul 2008.

LOPES, Ana Maria D’Ávila. A garantia do conteúdo essencial dos direitos fundamentais. Revista de Informação Legislativa. a. 41 n. 164, p. 7- 16, out/dez 2004.

METZGER, J. O Código Florestal tem base científica? Conservação e Natureza, v.8, n.1, p. 92-99, 2010.

MILARÉ, Édis. Direito do ambiente. 4. ed. São Paulo: Revista dos Tribunais, 2005.

MIRANDA, Evaristo Eduardo de et al. O alcance da legislação ambiental e territorial. Agroanalysis, v. 12, $\mathrm{n}^{\mathrm{0}}$ 28, p. 1-6, 2008.

MOMOLI, Renata Santos. Dinâmica da sedimentação em solos sob matas ciliares. 109 p. Tese (Doutorado em Agronomia) - Universidade de São Paulo Escola Superior de Agricultura "Luiz de Queiroz”, Piracicaba, 2011.

MORAES, D. S de L.; JORDÃO, B. Q. Degradação de recursos hídricos e seus efeitos sobre a saúde humana. Rev. Saúde Pública, v. 36, n.3, p. 370-374, 2002.

REBELO, Aldo. Parecer ao projeto de lei $n^{o} 1876$ e apensados. Disponível em: http://www.camara.gov.br/internet/sileg/Prop_Detalhe.asp?id=17338. Acesso em: 20 nov. 2015 .

SARLET, Ingo Wolfgang; FENSTERSEIFER, Tiago. Breves considerações sobre os deveres de proteção do Estado e a garantia da proibição de retrocesso em matéria ambiental. Revista Magister de Direito Ambiental e Urbanístico. v. 35, n. 6, p. 18-52, abr-mai, 2011.

SPAROVEK, Gerd. et al. A revisão do Código Florestal brasileiro. Disponível em: http://www.scielo.br/scielo.php?script=sci_arttext\&pid=S0101-

33002011000100007\&lng=en\&nrm=isso. Acesso em: 05. dez. 2015.

SILVA, J.A.A. et al. O Código Florestal e a Ciência: contribuições para o diálogo. São Paulo: Sociedade Brasileira para o Progresso da Ciência, SBPC; Academia Brasileira de Ciências, ABC, 2011.

STF - SUPREMO TRIBUNAL FEDERAL. ADI 3540-1, Rel. Min. Celso de Mello. J. 1.09.2005. Disponível em: http://redir.stf.jus.br/paginadorpub/paginador.jsp?docTP=AC\&docID=387260 Acesso em: 13 jan. 2016.

TOLEDO, L.F. et. al. A revisão do Código Florestal Brasileiro: impactos negativos para a conservação dos anfíbios. Disponível em: http://www.biotaneotropica.org.br/v10n4/pt/abstract?article+bn00410042010. Acesso em: 04 dez. 2015.

TUNDISI, J.G.; TUNDISI, T.M. Impactos potenciais das alterações do Código Florestal nos recursos hídricos. Biota Neotropica, Campinas. v.10, n. 4, p. 67-76, 2010.

WILSON, Edward Osborne. A situação atual da diversidade Biológica. In: WILSON, Edward Osborne. Biodiversidade. Rio de Janeiro: Nova Fronteira, 1997. 
A Redução das Áreas de Preservação Permanente de Recursos Hídricos pelo Novo Código Florestal e o Princípio da Proibição Proteção Deficiente

WWF - BRASIL. Crise hídrica em São Paulo é denunciada na ONU. Disponível em: http://www.wwf.org.br/informacoes/?uNewsID=44823. Acesso em: 15 jan. 2015.

Artigo recebido em 28 de junho de 2016 e aceito em 15 de junho de 2017 